\title{
MODELING OF CHANGES IN SPECTRAL CHARACTERISTICS OF BREAD CRUST DURING BAKING
}

\author{
Zlatin Zlatev, Miglena Kazakova, Liliya Topuzova \\ Trakia University, Faculty of Technics and Technologies, \\ 38 Graf Ignatiev str., 8602, Yambol, Bulgaria, \\ e-mail: zlatin.zlatev@trakia-uni.bg
}

\begin{abstract}
The color of the crust is a significant feature of bread and bakery products. The formation of the color of bread crust depends on the physical and chemical characteristics of the raw materials used in the dough. The presentation of images of bread crust during baking by color models such as $R G B$ or Lab has many limitations, making it difficult to track its change. This paper describes experimental system for tracking change the color of the bread crust during baking. Four mathematical models are studied of change of coefficient area under curve of spectral characteristics of bread crust. An exponential model is fitted to the experimental data. The effects of the model parameters were also studied by sensitivity. It was proved that the obtained exponential mathematical model is adequate.
\end{abstract}

Keywords: Bread baking, Bread crust, Mathematical model, Spectral characteristics.

\section{I NTRODUCTION}

The color of the crust is a significant feature of bread and bakery products because, like other organoleptic characteristics - texture, aroma, taste, it influences consumer preferences $[13,14,15,16]$. The formation of the color of bread crust depends on the physical and chemical characteristics of the raw materials used in the dough such as water, active acidity $(\mathrm{pH})$, sugars and amino acids, and the baking conditions such as the relative humidity of the baking chamber, temperature, speed of Air, heat and mass exchange processes $[7,12,17,18]$.

From the point of view of bread making technology, the formation of a uniformly baked and pleasant appearance of bread crust is one of the goals in the automation of the bread baking process. It follows that control of the formation of the bread crust can be considered as an important stage of the bread making technology.

More commonly used techniques in assessing the surface characteristics of bread crust are the obtaining, processing and analysis of images, spectral and hyperspectral characteristics. The purpose of the report is to trace the change in the color of the bread crust during baking using techniques to obtain its optical characteristics.

\section{RELATED WORKS}

Current studies are related to the use of offline and on-line systems [2,5,6,14] for measuring the color of various agricultural and food products, as well as for measuring the color of the bread crust during baking.

Zanoni et al. [17] suggests that traceability of the color formation of bread crust is realized through the color difference $\Delta \mathrm{E}$. The authors create a mathematical model that describes the change in color difference in function of the temperature of the crust. The results are compared with studies on the heat and mass transfer processes reported by other authors.

Purlis et al. [12] apply a computer vision system to track the formation of the bread crust during baking. The authors point out that the use of spectral characteristics in the UV, VIS, IR

IRTIIE Vol. 5, No. 2, 2017 ISSN 1314-8788 (print), ISSN 1314-8796 (online), doi: 10.15547/artte.2017.02.004 


\section{IRTIIE \\ $Y^{2}$ \\ Ipplied Reseirlches in Technicis, Technologies and Bductition \\ Journal of the Faculty of Technics and Technologies, Trakia University https://sites.google.com/a/trakia-uni.bg/artte/}

range is not an appropriate tool for tracking the baking process. In this study, the authors applied image analysis by using the XYZ color model components and described the process as a function of baking temperature and water activity.

Castro et al. [3] apply a system for obtaining, processing and analyzing images for tracking the baking process. Measurements are in the Lab color model. Models in function of temperature, flour/sugar ratio and consumer acceptability were obtained. The authors state that the use of spectral characteristics in the UV, VIS, IR range are suitable for monitoring changes in water activity, active acidity, metal cations, sugars during baking, but can not be directly applied to trace alteration The color of the baking crust.

The review of publications related to the follow-up of bread crust color changes indicates that colorimetric methods using colorimeters and image acquisition, processing, and analysis systems are used in the known studies.

The spectral characteristics are more suitable for tracking the changes of physico-chemical parameters.

The presentation of images of bread crust during baking by color models such as RGB or Lab has many limitations, making it difficult to track its change.

The literature states that in this type of complex images it is convenient to use the full spectrum of the image $[8,19]$. Using the full spectrum of image requires converting RGB values into spectral characteristics in the visible range $[9,11]$.

\section{MATERIAL AND METHODS}

\subsection{Object of the study}

The object of the study are spectral characteristics of bread crust during baking. An automated bread making machine is set to program 1, $1000 \mathrm{~g}$ and baking rate "High". Program with duration of $2 \mathrm{~h}$ and $58 \mathrm{~min}$ was used.

Pictures are taken during the baking period in the machine from $53 \mathrm{~min}$ to $2 \mathrm{~h}$ and $58 \mathrm{~min}$ at an interval of $8 \mathrm{~min}$ for 5 loaves. Bread is prepared according to the requirements presented in [1]. The following ingredients are used to prepare the dough: flour $100 \%$, water $56 \%$, yeast $2 \%$, salt $1,5 \%$.

\subsection{Experimental setup}

The general appearance of the laboratory equipment used is shown in Figure 1. A color digital camera DFK41AU02 with $1 / 2$ "CCD, $1280 \times 960$ pixels is used for capturing. The illumination is provided by a round luminescent lamp above the operating stage. A software application for image processing and analysis is enabled on the personal computer. The bread is baked in an automated machine [20] Moulinex Home Bread. The whole set is mounted on a stand with a shoulder strap, providing a change in the shooting height of the video camera.

\subsection{Convertion of color components to spectra}

A method is used to represent the values of the RGB color model in the form of reflectance spectra from the visible spectral range. The techniques for convertion of RGB values into spectra presented in $[8,9]$.

IRTIIE Vol. 5, No. 2, 2017 ISSN 1314-8788 (print), ISSN 1314-8796 (online), doi: 10.15547/artte.2017.02.004 


\section{ARTTL $Y$} Ipplied Resseirthes in Technics, Technologies and Bductition Journal of the Faculty of Technics and Technologies, Trakia University https://sites.google.com/a/trakia-uni.bg/artte/

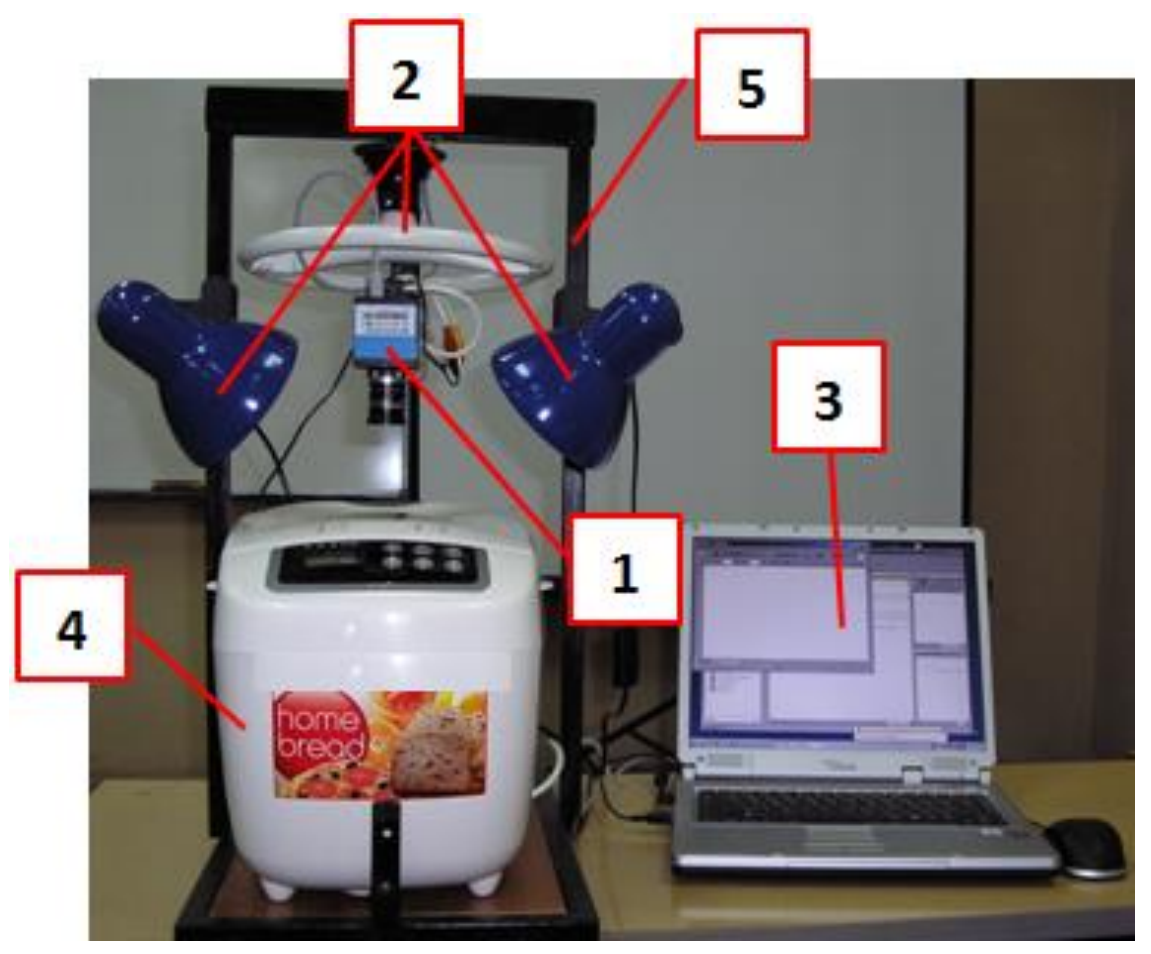

1-Video camera

2-Light system

3-Personal computer with software

4-Automated bread

machine

5-Mounting stand

Figure 1. Laboratory stand - general view

\subsection{Area under curve}

The area under curve (AUC) is used in the identification of processes for their comparison. To calculate this criterion, a function is used:

$$
A U C=\int_{a}^{b} f(x) d x
$$

The coefficients of the models used for the evaluation of the output data to the AUC are determined by autoregression model in Matlab [4].

\subsection{Models of the change for area under the curve}

The CurveFitting Toolbox in Matlab was used to obtain the models.

\subsection{Sensitivity analysis of models}

The sensitivity analysis is designed to determine the extent to which model output variables are affected by moderate changes to the model input. The sensitivity test can provide a general assessment of the accuracy of the model when used to evaluate alternative models as well as detailed information to overcome the errors at different parameter values [10]. A simplified deterministic approach was used in which the model parameters obtained were set by $\pm 10 \%$ of their values. Charts of the error module are analyzed at elevated and decreased values of the model parameters. If the output variables of the model differ significantly, then the output is sensitive to the specification of the input distributions and therefore they must be precisely defined.

IRTTIC Vol. 5, No. 2, 2017 ISSN 1314-8788 (print), ISSN 1314-8796 (online), doi: 10.15547/artte.2017.02.004 


\section{ARTTIE $Y$}

Ipplied Resseirthes in Technics, Technologies and Bductition

Journal of the Faculty of Technics and Technologies, Trakia University https://sites.google.com/a/trakia-uni.bg/artte/

\section{RESULTS AND DISCUSSION}

Figure 2 shows the spectral characteristics of bread crust during baking. The characteristics are obtained by converting the RGB color components into spectral characteristics. The graphs show that in certain spectral ranges there are overlapping characteristics, while in others they are too close to each other, which would make it difficult to distinguish them and track their change.

Figure 3 is a graph showing the change in AUC during the baking period. There is a decrease in the values of this coefficient during the baking period.

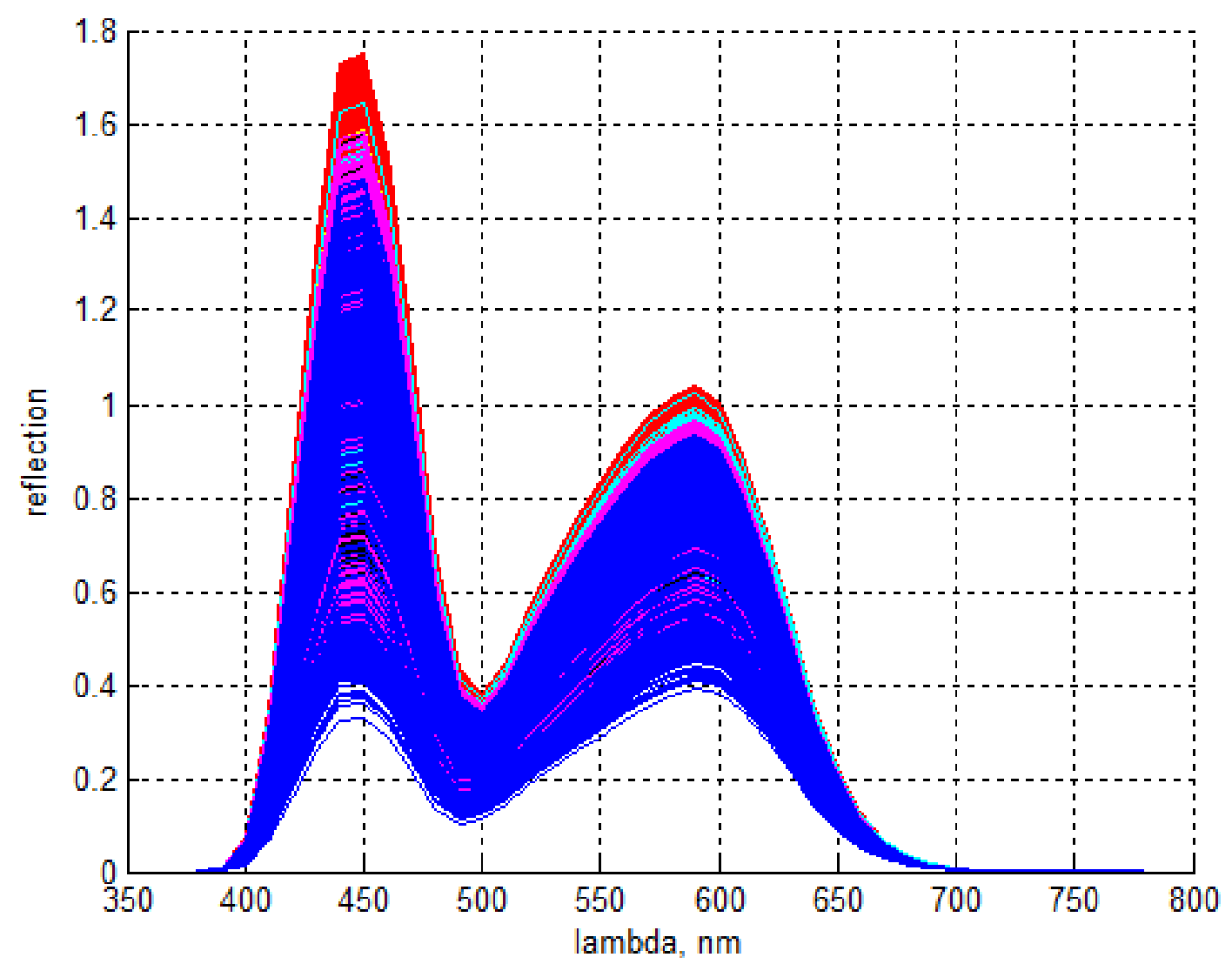

Figure 2. Spectral characteristics of bread crust during baking
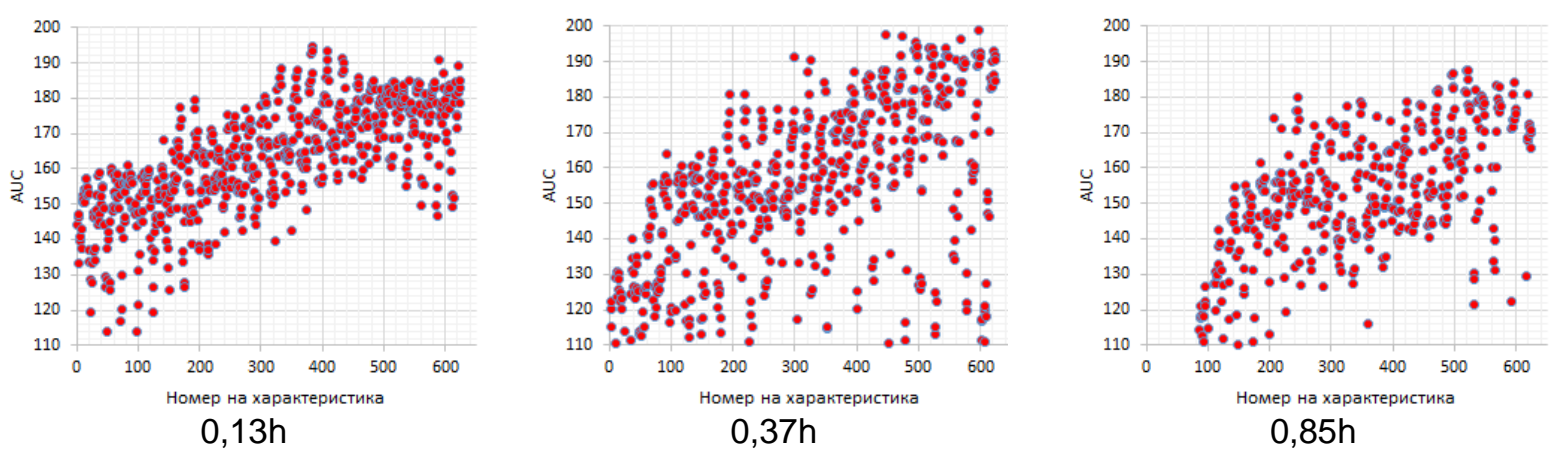

Figure 3. Changes in the coefficient AUC of spectral characteristics

IRTIIE Vol. 5, No. 2, 2017 ISSN 1314-8788 (print), ISSN 1314-8796 (online), doi: 10.15547/artte.2017.02.004 


\section{IRTTIE}

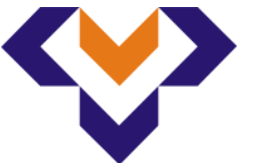

Ipplied Researrorches in Technics, Technologies and Bductition

Journal of the Faculty of Technics and Technologies, Trakia University https://sites.google.com/a/trakia-uni.bg/artte/

For modeling the curve of bread crust spectral characteristics changes, experimentally captured data and calculations the variance of the area under curve (AUC) were used.

Figure 4 shows the change in the mean values of AUC.

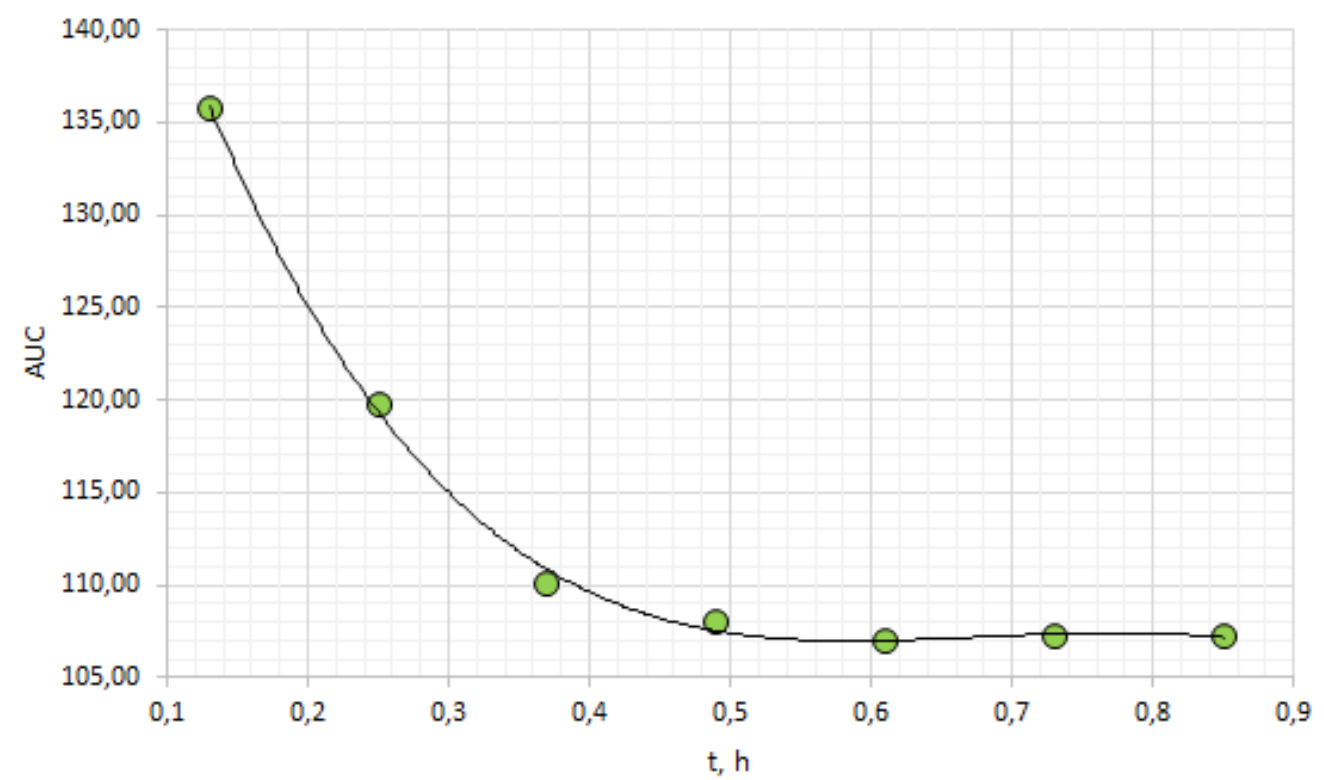

Figure 4. Changes in mean values of AUC coefficient

Table 1 shows the four models used. Parameters of coefficient of determination $\left(R^{2}\right)$, sum of squired (SSE) and root mean squired error (RMSE) are specified. The coefficients of the models used and the range of their variation are given in brackets.

The coefficient of determination for all models is $R^{2}=0,98-0,99$. SSE and RMSE error values are used as criteria for model selection.

Table 1. Models used for representation of the changes of mean values of AUC

\begin{tabular}{|c|c|c|c|c|c|}
\hline Model & Formula & Coefficients & $\mathbf{R}^{2}$ & SSE & $\underset{E}{R M S}$ \\
\hline Exponential & $y=a e^{b x}+c e^{d x}$ & $\begin{array}{l}a=76,73 \quad(63,75,89,71) \\
b=-5,732 \quad(-9,153,-2,312) \\
c=98,27 \quad(79,15,117,4) \\
d=0,09952 \quad(-0,1283 \\
0,3273)\end{array}$ & 0,997 & 2,034 & 0,823 \\
\hline Power & $y=a x^{b}+c$ & $\begin{array}{l}a=2,749 \quad(-2,473,7,971) \\
b=-1,226 \quad(-2,06,-0,3929) \\
c=102,6 \quad(94,19,111)\end{array}$ & 0,983 & $\begin{array}{c}11,71 \\
0\end{array}$ & 1,711 \\
\hline Polynomial & $y=a_{3} x^{3}+a_{2} x^{2}+a_{1} x+a_{0}$ & $\begin{array}{l}a_{0}=164,3 \quad(158,170,6) \\
a_{1}=-269,4 \quad(-320,6,-218,1) \\
a_{2}=414,1 \quad(296,9,531,2) \\
a_{3}=-207,5 \quad(-286,5,-128,5)\end{array}$ & 0,998 & 1,192 & 0,630 \\
\hline Rational & $y=\frac{a_{2} x^{2}+a_{1} x+a_{0}}{x+b_{1}}$ & $\begin{array}{l}a_{1}=31,5 \quad(-16,56,79,56) \\
a_{2}=65,16 \quad(7,488,122,8) \\
a_{3}=31,33 \quad(-21,6,84,25) \\
b_{1}=0,1667 \quad(-0,1762, \\
0,5095)\end{array}$ & 0,996 & 2,808 & 0,968 \\
\hline
\end{tabular}

IRTTIE Vol. 5, No. 2, 2017 ISSN 1314-8788 (print), ISSN 1314-8796 (online), doi: 10.15547/artte.2017.02.004 


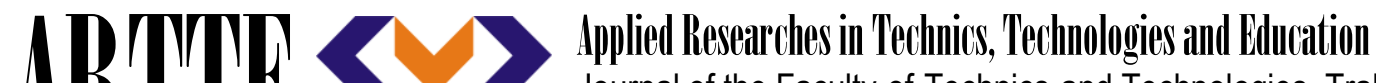 Journal of the Faculty of Technics and Technologies, Trakia University https://sites.google.com/a/trakia-uni.bg/artte/}

The lowest values of these errors are the exponential and the polynomial model, which describe the experimental data with sufficient precision.

The polynomial model, although having a high coefficient of determination and low error rates, has the disadvantage that oscillation of the resulting curve pattern occurs when increasing its order.

An exponential model is chosen because many of the biotech processes have an exponential character of changing their metrics $[16,18]$.

The sensitivity analysis of the exponential model shows that the smallest sensitivity in the initial point of the baking process.

The sensitivity of the tested parameter is greatest in the middle and at the end of the process.

Figure 5 shows a sensitivity chart of the selected model when changing its parameter values within a range of $\pm 10 \%$. The output values of the model differ significantly when changing the parameters within this range, indicating that the output is sensitive to the specification of the input distributions and therefore they must be precisely defined.

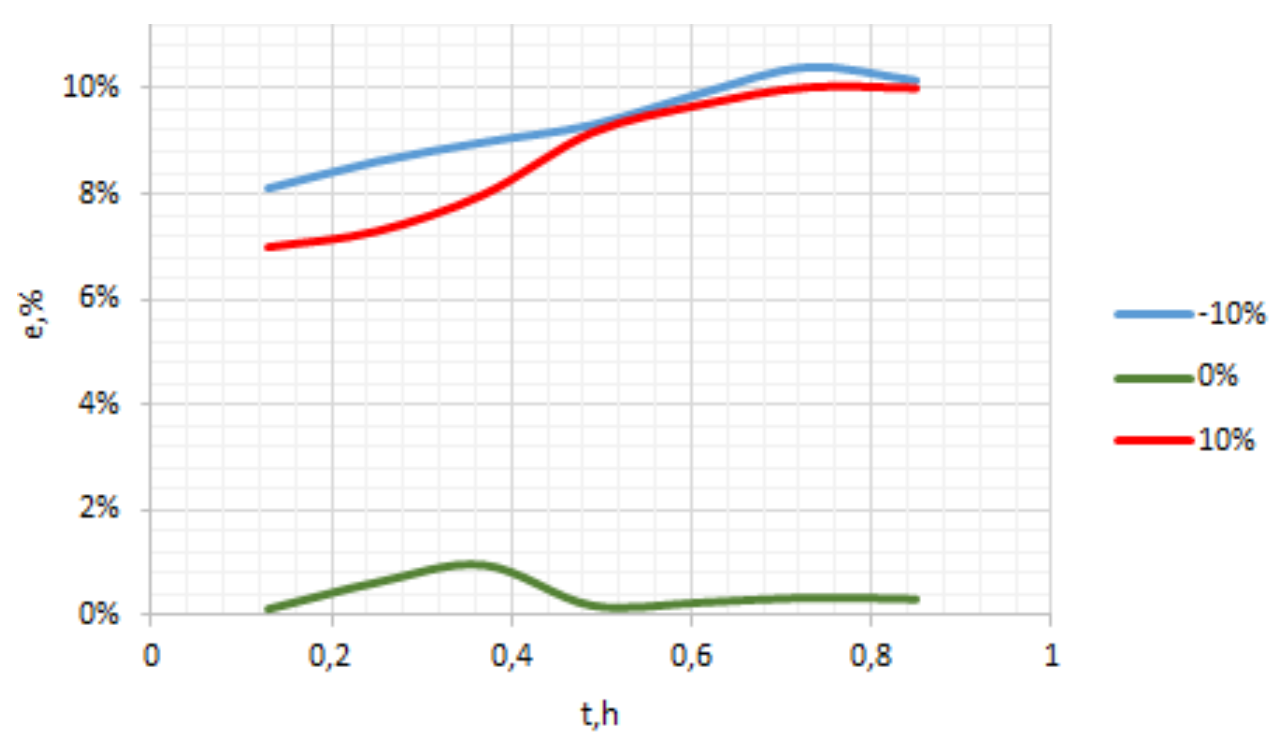

Figure 5. Error changes in decreasing and increasing the values of parameters of the model

In order to assess the extent to which the exponential model describes the baking roast color process, the results for this process and the Student criterion method are used, which at the available data have degrees of freedom $k=n-1$, where $n$ is The number of experimental data. Data was used to track the changes of the AUC coefficients of spectral characteristics that were not applied when searching for a suitable model to describe the experimental data.

The calculated value of the Student's criterion is $t_{\text {calculated }}=0,89$, the critical value at degrees of freedom $k=624$ is $t_{\text {critical }}=1,96$.

Because the calculated value of the criterion is less than the critical, the exponential model is adequate and can be used to track the change of the bread crust during baking.

\section{CONCLUSION}

The proposed experimental setup for tracking the bread baking process for can be used to create kinetic curves for this process.

IRITIE Vol. 5, No. 2, 2017 ISSN 1314-8788 (print), ISSN 1314-8796 (online), doi: 10.15547/artte.2017.02.004 


\section{IRT'TE

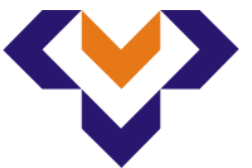 \\ Ipplied Reseirlches in Technicis, Technologies and Bductition \\ Journal of the Faculty of Technics and Technologies, Trakia University https://sites.google.com/a/trakia-uni.bg/artte/}

An analysis of errors SSE and RMSE determines that the experimental data is described with sufficient precision with a third-order polynomial model and an exponential model. For these models a generalized curve of the bread crust spectral characteristics was obtained.

The exponential model was selected and its sensitivity is assessed. The results of this assessment show that the model is sensitive to the change in its parameters and depends on the change in the other factors involved in the change in the surface features of the bread crust. Measuring these parameters and finding their relationship with the color change of the bread crust during baking will be the subject of further research.

The adequacy of the exponential model, which determines the possibility to use it to analyze the bread baking process, has been proven.

\section{ACKNOWLEDGMENTS}

The work on this article is related to scientific project 6.OUP/ 25.04.2017 "Construction of laboratory for photogrammetric and remote measurement methods".

\section{REFERENCES}

[1] Approved standard "Bulgaria", "White bread”, № 02/2011 (in Bulgarian).

[2] Baycheva S., Application of devices of measurement of colour in analysis of food products. Journal of Innovation and entrepreneurship, year IV, vol.4, 2016, ISSN 13149180, pp. 43-59.

[3] Castro W., J. Oblitas, T. Chuquizuta, H. Avila-George, Application of image analysis to optimization of the bread-making process based on the acceptability of the crust color, Journal of Cereal Science, vol.74, 2017, ISSN: 0733-5210, pp. 194-199.

[4] Estimate parameters of AR model for scalar time series, https://www.mathworks.com/help/ident/ref/ar.html (accessed 27.01.2017).

[5] Gaazi B., S. Atanasov, P. Daskalov, Ts. Georgieva, V. Nedeva, Application of wireless sensor networks as a tool for the building of information and advisory system in precision agriculture, Proceedings of ICTTE, October 30-31 2014, Yambol, Bulgaria, ISSN 13149474, pp. 1-6.

[6] Gaazi B., S. Atanasov, P. Daskalov, Ts. Georgieva, V. Nedeva, Application of wireless sensor networks in management system of technological processes in precision agriculture, Proceedings of ICTTE, October 30-31 2014, Yambol, Bulgaria, ISSN 13149474, pp. 1-6.

[7] Georgieva A., I. Dimov, Investigation of possibilities of bread enriched with dried coffee blend "Inca" Part 2: The quality of enriched white bread, Food science and technology, vol.1, №22, 2013, ISSN: 2073-8684, pp. 61-64.

[8] Glassner, A. S. How to derive a spectrum from an RGB triplet. IEEE Computer Graphics and Applications 9, 4 (July 1989), pp. 95-99.

[9] Hall R., Color reproduction and illumination models, Techniques for computer graphics, Springer-Verlag, 1987.

[10] Ivanova D., N. Valov, V. Stoyanov, I. Valova, Modeling the kinetic curves of apricot drying, Proceedings of University of Ruse, vol. 52, ser.3.1, 2011, pp. 170-174 (in Bulgarian)

[11] Mladenov, M., S. Penchev, M. Deyanov, Complex assessment of food products quality using analysis of visual images, spectrophotometric and hyperspectral characteristics. International Journal of Engineering and Innovative Technology (IJEIT), Vol. 4, Iss.12, 2015, ISSN: 2277-3754, pp. 23-32.

IRITIE Vol. 5, No. 2, 2017 ISSN 1314-8788 (print), ISSN 1314-8796 (online), doi: 10.15547/artte.2017.02.004 


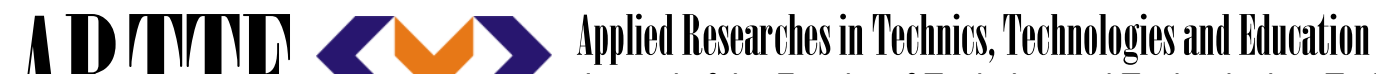 Journal of the Faculty of Technics and Technologies, Trakia University https://sites.google.com/a/trakia-uni.bg/artte/}

[12] Purlis E., V. O. Salvadori, Modelling the browning of bread during baking, Food Research International, vol.42, 2009, ISSN: 0963-9969, pp. 865-870.

[13] Vanin F, T. Lucas, G. Trystram, Crust formation and its role during bread baking, Trends in Food Science \& Technology, vol.20, 2009, ISSN: 0924-2244, pp. 333-343

[14] Walker S., K. Seetharaman, A. Goldstein, Characterizing physicochemical changes of cookies baked in a commercial oven. Food Res. Int., vol.48, No.1, 2012, pp. 249-256.

[15] Wu D., D-W. Sun, Colour measurements by computer vision for food quality control - A review, Trends Food Sci. Technol., vol.29, No.1, 2013, pp. 5-20.

[16] Yankov K., Identification of Effective Doses in Binary Mixtures, Proc. Int. Conf. on Information Technologies (InfoTech-2014) St. Constantine and Elena resort, Bulgaria, sept.18-20, 2014, ISSN 1314-1023, pp. 316-324.

[17] Zanoni B., C. Peri, D. Bruno, Modelling of Browning Kinetics of Bread Crust During Baking, Lebensmittel-Wissenschaft \& Technologie, vol. 28, 1995, ISSN: 0023-6438, pp. 604-609.

[18] Zhelyazkova M., I. Taneva, Statistical modeling of the process syneresis of the production of yogurt with water extract of Rosa canina, Journal of Pharmacognosy and Phytochemistry, vol.5, No.2, 2016, ISSN: 2278-4136, pp. 204-206.

[19] Zlatev Z., G. Shivacheva, A. Dimitrova, Recognition of object areas of foodstuffs with document camera by colorimetric methods, Proceedings of University of Ruse, vol. 54, No.10.2, 2015, ISSN 1311-3321, pp. 175-179 (in Bulgarian).

[20] Zlatev Z., Modeling of color changes in bread crust during baking, ICTTE International Conference on Technics, Technologies and Education, Faculty of Technics and Technologies, Trakia University, October 30-31 2014, ISSN 1314-9474, pp. 680-685.

IRTIIE Vol. 5, No. 2, 2017 ISSN 1314-8788 (print), ISSN 1314-8796 (online), doi: 10.15547/artte.2017.02.004 